\title{
The battle against Coronavirus disease 2019 (COVID-19) in the Kingdom of Saudi Arabia
}

\section{Public health perspective}

Sultan T. Al-Otaibi, MBBS, FRCPC.

\begin{abstract}

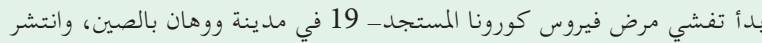

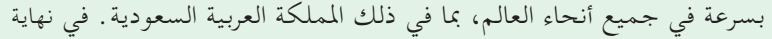

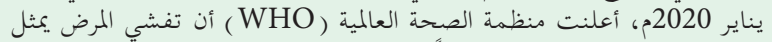

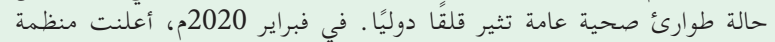

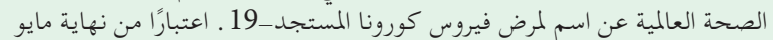

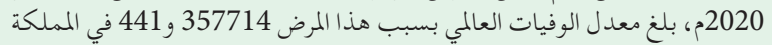

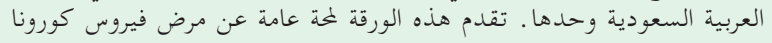

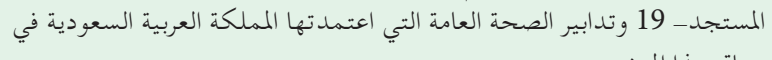

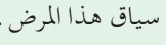

Coronavirus disease 2019 (COVID-19) which was initially reported in the Chinese city of Wuhan has now spread unprecedented all over the world, including the Kingdom of Saudi Arabia (KSA). The World Health Organization declared this outbreak as a public health emergency of international concern during late January 2020 while the announcement of this viral infectious condition was made as COVID-19 disease during February 2020. As of late May 2020, the global death rate due to COVID-19 was 357,714 and 441 in KSA alone. This review provides an overview of COVID-19 and the public health measures adopted by KSA in the context of COVID-19.

Keywords: Coronavirus disease (COVID-19), severe acute respiratory syndrome coronavirus 2 (SARS$\mathrm{CoV}-2$ ), public health perspective, pandemic

Saudi Med J 2020; Vol. 41 (12): 1285-1291 doi: 10.15537/smj.2020.12.25459

From the Department of Public Health, College of Public Health, Imam Abdulrahman Bin Faisal University, Dammam, Kingdom of Saudi Arabia.

Address correspondence and reprint request to: Dr. Sultan T. Al-Otaibi, Associate Professor, Department of Public Health, College of Public Health, Imam Abdulrahman Bin Faisal University. Dammam, Kingdom of Saudi Arabia.E-mail: salotaibi@iau.edu.sa ORCID ID: https://orcid.org/0000-0001-8234-7187
Coronavirus disease-2019 (COVID-19) is caused by a novel coronavirus known as Severe Respiratory Syndrome Coronavirus 2 (SARS-CoV-2), mainly resulting in respiratory symptoms that affect humans and animals. Coronavirus disease outbreak first began in Foshan, Guangdong, China in November 2002. In 2013, the Middle East Respiratory Syndrome Coronavirus (MERS-CoV) outbreak was reported in the middle east region, with similar clinical manifestations of SARS. ${ }^{1-4}$ In December 2019, COVID-19 was first reported in the Chinese City of Wuhan, and has now become a pandemic with great public health concern.,

On December 31, 1999, clusters of pneumonia cases with unknown etiological agent were reported by the health authority of Wuhan, China. ${ }^{7}$ Forty-one cases of a mysterious disease and one death were reported on January 11, 2020. The Chinese authorities reported to the World Health Organization (WHO) a novel CoV was identified in a hospitalized person with pneumonia in Wuhan. ${ }^{8}$

Virus and pathogenesis. Coronavirus disease2019 is caused by SARS-CoV-2. This is an enveloped ribonucleic acid virus and a member of the family Coronaviridae and Order Nidovirales. ${ }^{9}$ As identified in China, SARS-CoV-2 is zoonotic in origin and most likely related to bat coronavirus (possible original host). ${ }^{8}$ Severe Respiratory Syndrome-COV-2 is genetically different from SARS-CoV and MERS-CoV. ${ }^{10}$

The pathophysiology of COVID-19 is not well understood. ${ }^{11}$ It was postulated that this virus binds to the cells of epithelial layer in the upper respiratory track and replicate. Angiotensin-converting enzyme 2 (ACE2) is the principal receptor for SARS-CoV2. In this stage, the virus could be detected in nasal swabs while the patient is asymptomatic. In few days, the virus migrates to the lower respiratory tract triggering innate immune response with clinical manifestations and the virus can be identified by nasal swab or sputum as well as the early markers of the immune system. ${ }^{12-15}$ Usually, 
most of these cases are mild, but approximately 20\% become severe and develop pulmonary infiltrates where the virus infects alveolar type 2 cells, which eventually undergo apoptosis and die releasing toxins that get exchanged in the lungs. Recovery depends on the host immune response; hence, elderly individuals are at a higher risk due to diminished immune response and the ability to repair damaged epithelium. ${ }^{16}$

Epidemiology. RO is a mathematical expression that shows how contagious an infectious disease is. It is also termed as the reproduction number indicating the average number of people who may contract a contagious disease from one person with the disease. This RO concept is particularly applicable to a population who were previously free of infection and have not been vaccinated. ${ }^{17}$

According to a recent study, the RO for COVID-19 is 5.7, which indicates that COVID-19 is highly contagious and approximately double an earlier RO estimate of 2.2-2.7. ${ }^{18-22}$ Therefore, advanced surveillance systems, tracing primary and secondary contacts, quarantining, and social distancing measures are required to contain the transmission of this virus. ${ }^{18}$

As of the end of May 2020, the spokesman of the Ministry of Health, Dr. Mohamed Abd Al-Aly, stated that "the RO as 4 at the beginning of the pandemic. If the $\mathrm{RO}$ is above one, each infected patient would lead to more than one new case of COVID-19, and therefore, the disease would spread exponentially, resulting in an outbreak. If $\mathrm{RO}$ was below one, the disease would shrink and eventually die out". ${ }^{23}$

Herd immunity (community immunity) against a pathogen could be achieved when a large proportion of a community (85\% to $90 \%)$ develop immunity either through active vaccination or through prior infection, which could stop further transmission of the pathogen. ${ }^{24}$ However, it was concluded that herd immunity is not the best option to stop the transmission of the virus because no vaccines or specific antivirals for COVID-19 has been discovered. ${ }^{25}$ Furthermore, natural immunity is unlikely due to a lack of evidence to support the presence of antibodies in the serum against SARS-CoV-2 among the infected persons to protect them from another cycle of infection. ${ }^{26}$

The incubation period for COVID-19 is 2-14 days. $^{27,28}$ Coronavirus disease-2019 is more common

Disclosure. Authors have no conflict of interests, and the work was not supported or funded by any drug company. between the age of 35 and 59 years, but severe cases have been reported in $>65$ years, particularly those with comorbidities such as cardiovascular diseases, stroke, renal, pulmonary, obesity, hypertension, and diabetes mellitus or immunocompromised patients. ${ }^{29-31}$ Children $<15$ years old are less likely to be infected with COVID-19, usually with mild symptoms and this is due to the under development of ACE2 in children. ${ }^{32,33}$ Men and women both reported similar prevalence rates, while men are at a higher risk of adverse outcomes with higher mortality rate, independent of age. ${ }^{34}$ On the contrary, pregnancy is not a risk factor for COVID-19 infection. ${ }^{33}$ Another study conducted by a public health panel and collaborated by the WHO on April, 2020, reported that smokers were at higher risk of adverse outcomes of the disease than non-smokers. ${ }^{35}$

Transmission of COVID-19. A cluster of similar cases among families indicates person-to-person transmission of COVID-19 via respiratory droplets when the patient coughs or sneezes in close contact. ${ }^{36,37}$ Wuhan's dense population and transport status played a major role in the outbreak of COVID-19. ${ }^{17}$

Clinical features of COVID-19. Fever (99\%), fatigue $(70 \%)$, cough $(59 \%)$, shortness of breath $(55 \%)$, and loss of appetite (40\%), and body aches (35\%) are the presenting symptoms of COVID-19 disease. ${ }^{38,39}$ Multiple complications occur in severe cases, including hypoxemia, acute respiratory distress syndrome, disseminated intravascular coagulation, and multi-organ failure and death. . $^{31,39,40}$

The Ministry of Health (MOH), Saudi Arabia published evidence-based COVID-19 guidelines. These scientific guidelines (clinical guidelines, diagnosis, therapeutic protocols, and preventive measures) have been approved by the $\mathrm{MOH}$ for health practitioners to handle patients with COVID-19. The guidelines are updated on a regular basis. ${ }^{41}$

Characteristics of COVID-19 in KSA. As of February 9, 2020, the global number of confirmed COVID-19 cases reached over 40,000, with the vast majority in mainland China and 910 deaths were reported in over 30 countries. ${ }^{42}$ On January 30, 2020, the WHO declared the disease as a public health emergency of international concern. ${ }^{43}$ Subsequently, as cases world over increased, on March 12, 2020, the WHO announced the outbreak as a pandemic due to the rapid increase in the number of COVID-19 cases, increasing severity, and high mortality rate worldwide. ${ }^{44}$

The COVID-19 pandemic in Saudi Arabia is part of the world pandemic. On March 2, 2020, the MOH confirmed its first case in the country where the index case was reported from Qatif, Eastern Province, KSA. ${ }^{45}$ 
As of March 20, 2020, a total of 65,000 individuals from all regions of KSA were screened for COVID-19 based on their clinical indications, contact tracing, or new travel record. Out of theses, 1,519 cases were tested positive for COVID-19 based on the quantitative RT-PCR testing of nasopharyngeal samples, carried out at the National Health Laboratory. Age of these cases were range of 14-70 with majority (30.5\%) between age 26-35. Males were the majority (54.3\%). The distribution of these cases across KSA is shown in Figure 1 where the majority of these cases (40\%) from the Western region (Jeddah, Makkah, and Madinah). ${ }^{46}$

As of May 28, 2020, the number of cases of this disease in KSA reached 80,185, 441 deaths, and 54,553 recovered. ${ }^{47}$

Currently, $\mathrm{MOH}$ of KSA provides major administrative and financial support for healthcare services in 484 hospitals (45,729 beds) along with 2037 primary healthcare centers (PHCs). This becomes approximately $60 \%$ of the health services that the country supports its citizens. The private healthcare sectors in KSA also contribute to the health services. The private sector amounts to 125 hospitals $(11,833$ beds) and 2218 dispensaries and clinics. ${ }^{48}$

At the present time, there are 2337 Intensive Care Units (ICU) in Saudi Hospitals. Furthermore, KSA added an extra 2199 ICU COVID-19 beds in various hospitals across the kingdom. ${ }^{49}$

In addition, 500 bed field hospitals were opened across KSA to manage COVID-19 cases that need moderate medical care and those who have mild symptoms. ${ }^{50}$
It should be noted that activities of health departments in the hospitals were temporarily put on hold and devoted to care for COVID-19. Elective surgical procedures in the hospitals were cancelled and telemedicine were utilized globally including KSA to control and minimize transmission of COVID-19 among patients and/or healthcare professionals..$^{51,52}$

Public health measures. Advice for the public, ${ }^{44}$ were WHO encourages general public to take care of their health and protect others by: a) frequent hand washing in water with soap, or use of sanitizer gels when hand washing is not possible, b) practicing social distancing (keep a distance of one meter [3 feet] between self and anyone who is coughing or sneezing); c) discouraging touching eyes, nose, and mouth; d) practicing respiratory hygiene (example: to cover mouth and nose with bent elbow or tissue when coughing or sneezing, then disposing of the used tissue immediately); e) reaching out to medical care in case of fever, cough, and breathing difficulty, f) staying informed and following advisories given by healthcare providers, national and local public health authorities, or employers on how to protect self and others from COVID-19.

On the contrary, the government of KSA implemented public health measures directed towards individuals, communities, and institutions. ${ }^{53,54}$ These measures include the following: i) Personal measures aim to confine individual-to-individual spread, ensure people and their contacts, and diminish pollution of much of the time contacted surfaces. Individual measures incorporate regular hand cleanliness,

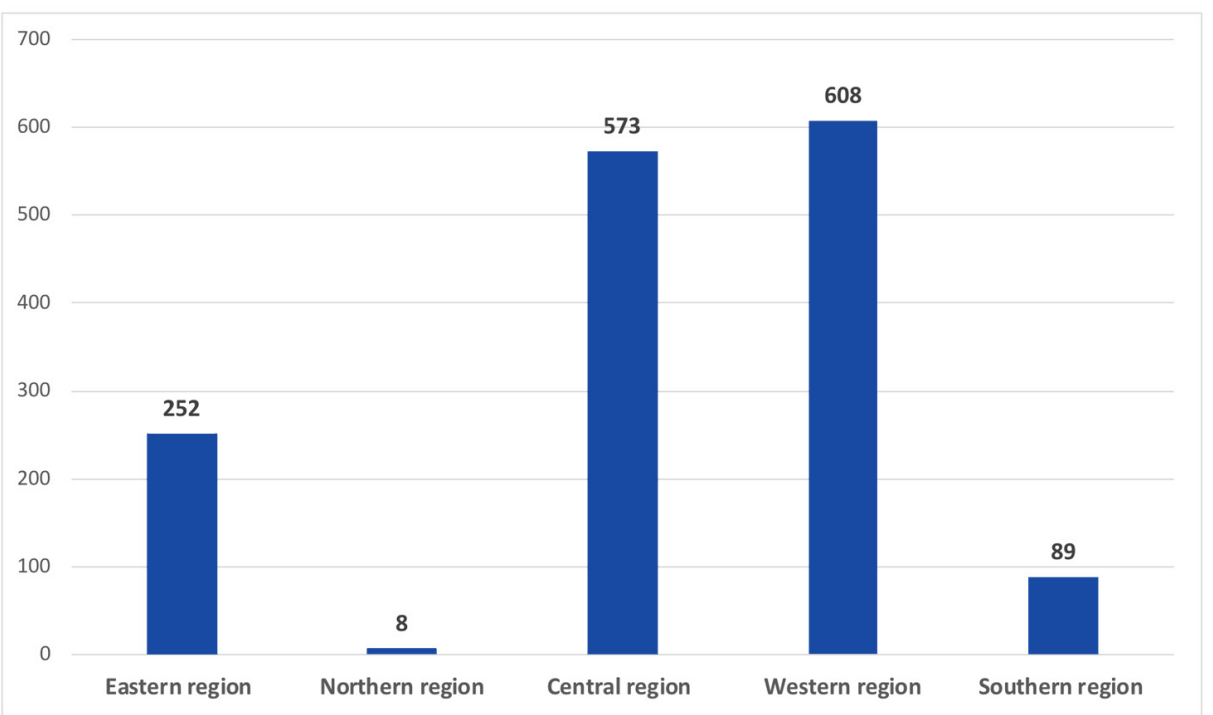

Figure 1 - Distribution of Coronavirus disease -19 across Saudi Arabia. ${ }^{46}$ 
respiratory decorum, utilization of covers assuming sick or taking care of someone unwell, and ecological cleaning and purification at home. ${ }^{55,56}$ Examples of these personal measures are washing hands, social distancing, personal hygiene, and staying home. ${ }^{39}$ ii) Physical and social distancing measures in the community locations control spread of virus from contaminated individuals to those who are not tainted and protect those in danger of creating a genuine ailment. These measures include physical separation, decrease or wiping out mass social gatherings, and staying away from crowded spaces in various settings (such as public transport, theaters, restaurants, and mosques), telecommuting, staying at home, and supporting adjustments for working environments and educational schools. ${ }^{57,58}$ These include distance learning (online education) for schools, which has proved to be a success story in the KSA. ${ }^{59}$ Mass gatherings were prohibited by the government of KSA in mosques, sports events, shopping malls, conferences, and festivals. ${ }^{60}$

Furthermore, considering the dangers of the malady and contaminations spreading in crowded gathering where it is hard to keep up safe social distancing among the people assembled. The harm in Makkah and Madinah Al Munnawara were briefly shut with suspending the passage of Umrah travelers while guaranteeing the wellbeing of people effectively present at the blessed destinations. It has been also concluded that Hajj during the current year (2020) will be held whereby an exceptionally set number of Muslims from different nationalities who as of now dwell in KSA, would have the option to perform it. This choice is taken to guarantee Hajj is acted in a sheltered way from a general wellbeing point of view while watching every single safeguard measure and the essential social distancing conventions to shield people from the dangers related with this pandemic and as per the lessons of Islam in saving the lives of individuals. ${ }^{61}$

Few shops and supermarkets have remained open; however, before entering these shops, customers had their temperatures checked and wore gloves and a face mask. Sterilizing gels were provided too. In addition, sneeze guards were installed at counters, point of sales, and payment of these shops.

Virus survival time differs by surface type as follow: ${ }^{62}$ a) copper: 4 hours, b) cardboard: 24 hours, c) stainless steel: 48 hours, d) plastic: 72 hours. The government of KSA supported businesses and implemented teleworking and virtual meetings.

iii) Movement measures plan to prevent infection started with one zone and then to the next. These measures included restricting movement of people,
Table 1 - Deaths of healthcare workers (HCWs) from COVID-19 pandemic. ${ }^{65,66}$

\begin{tabular}{lcc}
\hline Country & $\begin{array}{c}\text { Number of deaths } \\
\text { among HCWs }\end{array}$ & Date of report \\
\hline Italy & 120 & April 7, 2020 \\
Iran & 95 & April 16, 2020 \\
USA & 66 & April 15, 2020 \\
UK & 41 & April 14, 2020 \\
Spain & 26 & April 08, 2020 \\
Philippines & 24 & April 15, 2020 \\
China & 22 & February 15, 2020 \\
Indonesia & 17 & April 15, 2020 \\
Brazil & 17 & April 15, 2020 \\
France & 15 & April 10, 2020 \\
\hline
\end{tabular}

offering direction for travel, and masterminding systematic travel ahead of time to maintain a strategic distance from blockage at movement centers, including train stations, transport terminals, and air terminal. ${ }^{63}$ The government of KSA had suspended all domestic or international flights. Anyone coming from abroad, regardless of the destination, should undergo a mandatory quarantine in designated hotels for 2 weeks and released only if tested negative for COVID-19 on 2 separate tests.

iv) Special protection measures are targeted to shield special populace and vulnerable individuals, such as the elderly, healthcare workers and staff of institutions, and frontline responders. ${ }^{64}$

Healthcare workers. In KSA, protecting healthcare workers (HCWs) is a priority in this COVID-19 pandemic. Reportedly, HCWs have died from the disease, and it is believed that these deaths will likely increase as the pandemic progresses. Lack or improper wearing of personal protective equipment were incriminated as the cause of these deaths. ${ }^{65,66}$ Table 1 depicts the countries that have reported deaths of HCWs from the COVID-19 pandemic. ${ }^{65,66}$

On January 10, 2020, infection and prevention control guidance was published by the WHO to protect healthcare workers, recommending droplet (particles $\geq 5 \mu \mathrm{m}$ ) and contact precautions while caring for patients with COVID-19 and airborne (particles $<5 \mu \mathrm{m})$ precautions for aerosol-generating procedures conducted by HCWs during this pandemic. ${ }^{44}$

Medical and N95 masks can give adequate protection against respiratory viral infections, including that of 
coronavirus, for healthcare workers during non-aerosol generating patient care. ${ }^{67}$ Improper use of N95 may be worse than not using any. Wearing a "mask" may give a false sense of protection, discouraging other methods. Proper training on how to properly place and fit check the device and, more importantly, when it should or should not be used, is essential. A study suggested that cloth masks may increase the transmission of disease among hospital workers compared to controls, although regular surgical masks performed better than controls. ${ }^{68}$

Healthcare workers are heavily involved in active case surveillance and contact tracing. Active case surveillance occurs when the health department is proactive and contacting health care providers or laboratories for information about diseases. While this method is more costly and labor-intensive, it tends to provide a more complete estimate of disease frequency. ${ }^{69}$

Contact tracing aims at identifying and following up of individuals who may have encountered an infected person with COVID-19 and this will break the chain of transmission in the context of COVID-19.53,70

Occupational physicians should create workplace safety plans to return to work for employees during the pandemic. Resumption to duty policies for essential healthcare workers, may be examined into during this pandemic for practical reason in response to acute workforce shortages in key jobs and sectors. ${ }^{71}$

Post pandemic public health measures. The RO of COVID-19 approached one by May 30, 2020, indicating that the prevalence of COVID-19 in KSA is $<1 \%$ in the entire population. ${ }^{23}$ From May 30, 2020, the government of KSA started to ease public health measures for COVID-19 pandemic. $^{23}$ As per the COVID-19 Monitoring Committee, daytime curfew to be waived from May 28, 2020. ${ }^{72}$

In case of a second wave of SARS-CoV-2 or the virus mutates, one should consider the following: a) KSA has well-equipped hospitals and ICU with the ability to expand bed capacity. b) $\mathrm{MOH}$ of KSA updates the therapeutic protocols regularly. c) Testing for COVID-19 is robust, comprehensive, and reliable. d) Continuation of active case surveillance with a focus on high-risk groups for COVID-19, such as patients with cardiovascular diseases and diabetes and those from specific g) Geographical areas, such as Makkah and Madinah, where high cases of COVID-19 were reported. e) Gradual return to school and mosques. f) People of KSA should continue to practice frequent hand washing in warm water with soap or use of hand sanitizers; maintain social distancing; avoid touching eyes, nose, and mouth; and follow respiratory hygiene until the pandemic is over. g) Begin with the essential workers of all kinds. h) Continue to shield the vulnerable groups among the population.

In conclusion, the COVID-19 outbreak initially began in KSA on March 2, 2020 and it was declared a public health emergency of concern. As of May 30 2020, the confirmed deaths from COVID-19 was 441 in KSA alone. The public health measures introduced by the government of KSA brought the prevalence rate of COVID-19 to $<1 \%$. However, these measures were eased by May 30, 2020 in KSA.

Acknowledgment. The author extends thanks to Scribendi Editing Services who helped in editing and proofreading this manuscript.

\section{References}

1. Cui J, Li F, Shi ZL. Origin and evolution of pathogenic coronaviruses. Nat Rev Microbiol 2019; 17: 181-192.

2. Centers for Disease Control and Prevention. SARS Basics Fact Sheet [Updated 2017 December 6. Accessed 2020 August 16]. Available from URL: https://www.cdc.gov/sars/about/fs-sars. html

3. World Health Organization. SARS (Severe Acute Respiratory Syndrome). [Updated 2020. Accessed 2020 August 16] Available in URL: https://www.who.int/ith/diseases/sars/en/

4. Memish ZA, Perlman S, van Kerkhove MD, Zumla A. Middle East respiratory syndrome. Lancet 2020; 395: 1063-1077.

5. Zhu N, Zhang D, Wang W, Li X, Yang B, Song J, et al. A novel coronavirus from patients with pneumonia in China, 2019. N Engl J Med 2020; 382: 727-733.

6. World Health Organization. Archived: WHO Timeline COVID-19. [Updated 2019 December 31. Accessed 2020 August 16]. Available from URL: https://www.who.int/ news-room/detail/27-04-2020-who-timeline---covid-19

7. Chan JF, Yuan S, Kok KH, Kai-Wang K, Chu H, Yang J, et al. A familial cluster of pneumonia associated with the 2019 novel coronavirus indicating person-to-person transmission: a study of a family cluster. Lancet 2020; 395: 514-523.

8. World Health Organization. WHO Statement regarding cluster of pneumonia cases in Wuhan, China. [Updated 2020 January 9. Accessed 2020 August 8]. Availble from URL: https:// www.who.int/china/news/detail/09-01-2020-who-statementregarding-cluster-of-pneumonia-cases-in-wuhan-china

9. Richman DD, Whitley RJ, Hayden FG, editors. Clinical Virology, 4th ed. Washington, DC: ASM Press; 2016. 1243-1265

10. Zhou P, Yang XL, Wang XG, Hu B, Zhang L, Zhang W, et al. A pneumonia outbreak associated with a new coronavirus of probable bat origin. Nature 2020; 579: 270-273.

11. Lu R, Zhao X, Li J, Niu P, Yang B, Wu H, et al. Genomic characterization and epidemiology of 2019 novel coronavirus: implications for virus origins and receptor binding. Lancet 2020; 395: 565-574.

12. Mason RJ. Pathogenesis of COVID-19 from a cell biology perspective. Eur Respir J 2020; 55: 2000607.

13. Wan Y, Shang J, Graham R, Baric RS, Li F. Receptor recognition by novel coronavirus from Wuhan: An analysis based on decade-long structural studies of SARS. J Virol 2020; 94: e00127-20. 
14. Reyfman PA, Walter JM, Joshi N, Anekalla FR, McQuattiePimentel AC, Chiu S, et al. Single-cell transcriptomic analysis of human lung provides insights into the pathobiology of pulmonary fibrosis. Am J Respir Crit Care Med 2019; 199: 1517-1536.

15. de Wilde AH, Snijder EJ, Kikkert M, van Hemert MJ. Host factors in coronavirus replication. Curr Top Microbiol Immunol 2018; 419: 1-42

16. Wu Z, McGoogan JM. Characteristics of and important lessons from the coronavirus disease 2019 (COVID-19) outbreak in China: summary of a report of 72314 cases from the Chinese Center for Disease Control and Prevention. JAMA 2020; 323: 1239-1242.

17. Li Q, Guan X, Wu P, Wang X, Zhou L, Tong Y, et al. Early transmission dynamics in Wuhan, China, of novel coronavirusinfected pneumonia. N Engl J Med 2020; 1199-1207.

18. Sanche S, Lin Y, Xu C, Romero-Severson E, Hengartner N, Ke R. High Contagiousness and Rapid Spread of Severe Acute Respiratory Syndrome Coronavirus 2. Emerging Infectious Diseases 2020; 26: 1470-1477.

19. Natsuko Imai, Ilaria Dorigatti, Anne Cori, Christl Donnelly, Steven Riley, Neil M. Ferguson. Estimating the potential total number of novel Coronavirus cases in Wuhan City, China. Imperial College London COVID-19 Response Team 2020; 1-7.

20. Wu JT, Leung K, Leung GM. Nowcasting and forecasting the potential domestic and international spread of the 2019-nCoV outbreak originating in Wuhan, China: a modelling study. Lancet 2020; 395: 689-697.

21. Riou J, Althaus CL. Pattern of early human-to-human transmission of Wuhan 2019 novel coronavirus (2019-nCoV), December 2019 to January 2020. Euro Surveill 2020; 25: 2000058.

22. Du Z, Wang L, Cauchemez S, Xu X, Wang X, Cowling BJ, et al. Risk for transportation of 2019 novel coronavirus disease from Wuhan to other cities in China. Emerg Infect Dis 2020; 26: 1049-1052.

23. Arab News. The Coronavirus Pandemic: Ramadan gatherings cause COVID-19 cases among Saudi children, women to soar [Updated 2020 May 14. Accessed 2020 August 16]. Available form URL: https://www.arabnews.com/node/1674601/saudiarabia

24. Healthline. What Is Herd Immunity and Could Help Presvent COVID-19? Stats. [Updated 2020 April 2. Accessed 2020 August 16]. Available from URL: https://www.niaid.nih.gov/ diseases-conditions/coronaviruses-therapeutics-vaccines

25. Developing MERS and SARS therapeutics and vaccines. Available from URL: https://www.niaid.nih.gov/diseasesconditions/coronaviruses-therapeutics-vaccines

26. World Health Organization. "Immunity passports" in the context of COVID-19. [Updated 2020 April 24. Accessed 2020 August 16]. Available from URL: https://www.who.int/ Anews-room/commentaries/detail/immunity-passports-in-thecontext-of-covid-19

27. World Health Organization. Global surveillance for human infection with novel coronavirus (2019-nCoV). [Updated 2020. Accessed 2020 August 16]. Available from URL: https://apps.who.int/iris/bitstream/handle/10665/330857/ WHO-2019-nCoV-SurveillanceGuidance-2020.3-eng. pdf?sequence $=1$ \&isAllowed $=y$

28. Backer JA, Klinkenberg D, Wallinga J. Incubation period of 2019 novel coronavirus (2019-nCoV) infections among travellers from Wuhan, China, 20-28 January 2020. Euro Surveill 2020; 25: 2000062.
29. Sun J, He WT, Wang L, Lai A, Ji X, Zha X, et al. COVID-19: epidemiology, evolution, and cross-disciplinary perspectives. Trends Mol Med 2020; 26: 483-495.

30. Chang D, Lin M, Wei L, Xie L, Zhu G, Dela Crus CS, et al. Epidemiologic and clinical characteristics of novel coronavirus infections involving 13 patients outside Wuhan, China. JAMA 2020; 323: 1092-1093.

31. Chen N, Zhou M, Dong X, Qu J, Gong F, Han Y, et al. Epidemiological and clinical characteristics of 99 cases of 2019 novel coronavirus pneumonia in Wuhan, China: a descriptive study. Lancet 2020; 395: 507-513.

32. Shen K, Yang Y. Diagnosis, and treatment of 2019 novel coronavirus infection in children: a pressing issue. World J Pediatrics 2020; 16: 219-221.

33. Jin JM, Bai P, He W, Wu F, Liu XF, Han DM, et al. Gender differences in patients with COVID-19: focus on severity and mortality. Front Public Health 2020; 8: 152.

34. Chen H, Guo J, Wang C, Luo F, Yu X, Wei Zhang W, et al. Clinical characteristics and intrauterine vertical transmission potential of COVID-19 infection in nine pregnant women: a retrospective review of medical records. Lancet 2020; 395: 809-815.

35. World Health Organization. WHO statement: Tobacco use and COVID-19. [Upadtes 2020 May 11. Accessed 2020 August 16]. Available from URL: https://www.who.int/news-room/ detail/11-05-2020-who-statement-tobacco-use-and-covid-19

36. Phan LT, Nguyen TV, Luong QC, Nguyen TV, Nguyen HT, Le HQ, et al. Importation and human-to-human transmission of a Novel Coronavirus in Vietnam. N Engl J Med 2020; 382: 872-874.

37. Wang C, Horby PW, Hayden FG, Gao GF. A novel coronavirus outbreak of global health concern. Lancet 2020; 395: 470-473.

38. Harapan H, Itoh N, Yufikae A, Winardi W, Keam S, Te H et al. Coronavirus disease 2019 (COVID-19): A literature review. J Infect Public Health 2020; 13: 667-673.

39. Habibzadeh P, Stoneman EK. The Novel Coronavirus: A Bird's Eye View. Int J Occup Environ Med 2020; 11: 65-71.

40. Zaim S, Chong JH, Sankaranarayanan V, Harkyc A. COVID-19 and multi-organ response. Curr Probl Cardiol 2020; 8: 100618.

41. Ministry of Health. MOH Publications: COVID-19 Guidelines. [Updated 2020 September 28. Accessed 2020 August 16]. Available from URL: https://www.moh.gov.sa/en/ Ministry/MediaCenter/Publications/Pages/covid19.aspx

42. World Health Organization. Novel Coronavirus (2019-nCoV) Situation Report - 12.[Updated 2020 February 1 accessed 2020 August 16]. Available from URL: https://www.who.int/ docs/default-source/coronaviruse/situation-reports/20200201sitrep-12-ncov.pdf?sfvrsn $=273 \mathrm{c} 5 \mathrm{~d} 3552$

43. World Health Organization. WHO Timeline - COVID-19. [Updated 2020 June 29. Accessed 2020 August 16]. https:// www.who.int/news-room/detail/27-04-2020-who-timeline--covid-19

44. World Health Organization. WHO announces COVID-19 outbreak a pandemic. [Updated 2020 December 3. Accessed 2020 August 16]. Available from URL: http://www.euro.who. int/en/health-topics/health-emergencies/coronavirus-covid-19/ news/news/2020/3/who-announces-covid-19-outbreak-apandemic

45. Ministry of Health. "COVID 19 Dashboard: Saudi Arabia". Archived from the original on August 2020. [Updated 2020. Accessed 2020 August 16]. Available from URL: https:// covid19.moh.gov.sa/ 
46. Alsofayan YM, Althunayyan SM, Khan AA, Hakawi AM, Assiri AM. Clinical characteristics of COVID-19 in Saudi Arabia: A national retrospective study. J Infect Public Health 2020; 13: 920-925.

47. WorldOMeter. Saudi Arabia Coronavirus Cases. [Updated 2020 October 28. Accessed 2020 August 16]. Available from URL: https://www.worldometers.info/coronavirus/country/ saudi-arabial

48. Health statistical yearbook. Riyadh, Saudi Arabia, Ministry of Health, 2019. [Updated 2020 October 28. Accessed 2020 August 16]. Available from URL: https://www.moh.gov.sa/en/ Ministry/Statistics/book/Pages/default.aspx

49. English Al Arabia. ICUCOVID-19, extra beds in KSA. [Updated 2020 July 5. Accessed 2020 August 16]. Available from URL: https://english.alarabiya.net/en/coronavirus/2020/07/05/ Coronavirus-Saudi-Arabia-adds-2-199-ICU-beds-within-90days-across-Kingdom

50. Gulf News. Field hospitals in KSA. [Updated 2020. Accessed 2020 August 16]. Available from URL: https://gulfnews.com/ world/gulf/saudi/covid-19-500-bed-field-hospital-opens-injeddah-saudi-arabia-1.71928438

51. Hollander JE, Carr BG. Virtually perfect? Telemedicine for covid-19. N Engl J Med 2020; 382: 1679- 1681.

52. Moazzami B, Razavi-Khorasani N, Dooghaie Moghadam A, Farokhi E, Rezaei N. COVID-19 and telemedicine: Immediate action required for maintaining healthcare providers well-being. J Clin Virol 2020; 126: 104345.

53. Weqay, Saudi Center for Disease Control and Prevention. COVID-19 Coronavirus Disease Guidelines. [Updated 2020 May. Accessed 2020 August 16]. Available from URL: https://www.moh.gov.sa/Ministry/MediaCenter/Publications/ Documents/Coronavirus-Disease-2019-Guidelines-v1.2.pdf

54. Ministry of Health. Public Health. Novel Coronavirus (COVID-19). [Updated 2020. Accessed 2020 August 16]. Available from URL: https://www.moh.gov.sa/en/ HealthAwareness/EducationalContent/PublicHealth/Pages/ corona.aspx

55. World Health Organizatin. Critical preparedness, readiness, and response actions for COVID-19. [Updated 2020 June 24. Accessed 2020 August 16]. Available from URL: https://www. who.int/publications-detail/critical-preparedness-readinessand-response-actions-for-covid-19

56. World Health Organization. Non-pharmaceutical public health measures for mitigating the risk and impact of epidemic and pandemic influenza. [Updated 2020 October. Accessed 2020 Augugst 16]. Available from URL: https:// www.who.int/influenza/publications/public_health_measures/ publication/en/

57. World Health Organization. Key planning recommendations for mass gatherings in the context of the current COVID-19 outbreak. [Updated 2020 May 29. Accessed 2020 August 16]. Available from URL: https://www.who.int/publications/i/ item/10665-332235

58. World Health Organization. Considerations for school-related public health measures in the context of COVID-19 (Interim Guidance) ([Updated 2020 September 14. Accessed 2020 Augugst 16]. Available from URL: https://www.who.int/ publications-detail/considerations-for-school-related-publichealth-measuresin-the-context-of-covid-19

59. Arab News. Saudi education directorate launches remote teaching award. [Updated 2020 April 6, 2020. Accessed 2020 August 16]. Available from URL: https://www.arabnews.com/ node/1653771/saudi-arabia
60. World Health Organization. Country \& Technical Guidance - Coronavirus disease (COVID-19) Coronavirus disease (COVID-19) technical guidance: points of entry and mass gatherings. [Updated 2020. Accessed August 16]. Available from URL: https://www.who.int/emergencies/diseases/novelcoronavirus-2019/technical-guidance

61. Saudi Press Agency. Ministry of Hajj and Umrah. [Updated 2020 June 22. Accessed 2020 August 16]. Available from URL: https://www.spa.gov.sa/viewfullstory. php?lang=en\&newsid $=2100951$

62. Kampf G, Todt D, Pfaender S, Steinmann E. Persistence of coronaviruses on inanimate surfaces and their inactivation with biocidal agents. J Hosp Infect 2020; 104: 246-251.

63. European Centre for Disease Prevention and Control. Considerations for infection prevention and control measures on public transport in the context of COVID-19. [Updated 2020 April 29. Accessed 2020 August 16]. Available from URL: https://www.ecdc.europa.eu/en/publications-data/covid-19prevention-and-control-measures-public-transport

64. World Health Organization. Infection prevention and control for long-term care facilities in the context of COVID-19 [Updated 2020 January 30. Accessed 2020 August 30]. Available from URL: https://apps.who.int/iris/bitstream/ handle/10665/331508/WHO-2019-nCoV-IPC_long_term_ care-2020.1-eng.pdf

65. Hassanian-Moghaddam H, Zamani N, Kolahi A. COVID-19 pandemic, healthcare providers' contamination and death: an international view. Crit Care 2020; 208: 1-2.

66. Lo D. COVID-19: protecting health-care workers. Lancet 2020; 395: 922.

67. Bartoszko JJ, Farooqi MA, Alhazzani W, Loeb M. Medical Masks vs N95 respirators for preventing COVID-19 in healthcare workers: A systematic review and meta-analysis of randomized trials. Influenza Other Respir Viruses 2020; 14: 365-373.

68. MacIntyre CR, Seale H, Dung T, Hien NT, Nga P, Chughta A, et al. A cluster randomized trial of cloth masks compared with medical masks in healthcare workers. BMJ Open 2015; 5 : e006577.

69. Ministry of Health. Active Surveillance Detects COVID-19 Cases in Makkah and Madina. [Updated 2020 April 18. Accessed 2020 August 16]. Available from URL: https://www. moh.gov.sa/en/Ministry/MediaCenter/News/Pages/News2020-04-18-002.aspx

70. World Health Organization. Contact tracing in the context of COVID-19. [Updated 2020 May 10. Accessed 2020 August 16]. Available from URL: https://www.who.int/publicationsdetail/contact-tracing-in-the-context-of-covid-19

71. American College of Occupational and Environmental Medicine. COVID-19 Guideline for Occupational Health. [Updated 2020. Accessed 2020 August 16]. Available from URL: https://acoem.org/

72. Ministry of Health. Daytime Curfew to be Relaxed from Next Thursday, COVID-19 Monitoring Committee Says. [Updated 2020 May 26. Accessed 2020 August 16]. Available from URL: https://www.moh.gov.sa/en/Ministry/MediaCenter/News/ Pages/News-2020-05-26-001.aspx 